\title{
A comparison of the RIFLE and Acute Kidney Injury Network classifications for cardiac surgery-associated acute kidney injury: A prospective cohort study
}

\author{
Michael Haase, MD, ${ }^{\mathrm{a}, \mathrm{b}}$ Rinaldo Bellomo, MD, ${ }^{\mathrm{a}}$ George Matalanis, MD, FRACS, ${ }^{\mathrm{c}}$ Paolo Calzavacca, MD, ${ }^{\mathrm{d}}$ \\ Duska Dragun, MD, ${ }^{\mathrm{b}}$ and Anja Haase-Fielitz, PharmD ${ }^{\mathrm{a}, \mathrm{b}}$
}

\begin{abstract}
Objectives: There is an intense debate on whether the RIFLE (R-renal risk, I-injury, F-failure, L-loss of kidney function, E-end-stage renal disease) classification or its recent modification, the Acute Kidney Injury Network definition and classification system should be used to standardize research on acute kidney injury. In this study we compared these classifications with regard to (1) the detection of acute kidney injury, (2) their agreement according to the grading of acute kidney injury across classes, and (3) their prognostic value.
\end{abstract}

\begin{abstract}
Methods: We prospectively enrolled 282 cardiac surgery patients undergoing cardiopulmonary bypass and assigned a RIFLE and Acute Kidney Injury Network class to each patient. The incidence of acute kidney injury and in-hospital mortality across classes was compared by using the $\chi^{2}$ test, and their prognostic value was compared by using the area under the curve receiver-operating characteristic for in-hospital mortality.
\end{abstract}

Results: According to the RIFLE (45.8\%) or Acute Kidney Injury Network (44.7\%) classification, a similar proportion of patients had acute kidney injury. There was large agreement between classifications according to patients graded as having nonacute kidney injury; however, there was some disagreement across classes for staging the severity of acute kidney injury. The area under the curve for in-hospital mortality was similar for all classifications: 0.91 for the RIFLE classification (95\% confidence interval, 0.82-0.99) and 0.94 for the Acute Kidney Injury Network classification ( $95 \%$ confidence interval, $0.81-0.97 ; P=.6$ for area under the curve comparison).

Conclusions: In patients undergoing cardiac surgery, modifications of the RIFLE classification for acute kidney injury do not materially improve the clinical usefulness of the definition. Other factors, such as the applicability of the acute kidney injury definition and classification system to be applied, need to be considered. ( $\mathrm{J}$ Thorac Cardiovasc Surg 2009;138:1370-6)

Acute kidney injury (AKI) is a common complication after cardiac surgery with the use of cardiopulmonary bypass and is associated with substantial morbidity and mortality. ${ }^{1}$ Early recognition of AKI and standardized reporting on it are of importance. Until recently, however, there were more than 30 published definitions of AKI in use, rendering comparisons of and conclusions from studies in this field with regard to epidemiology, success of prevention or intervention, early recognition, and prognosis difficult if not impossible. In response to the lack of a standard definition and classification system for AKI, the Acute Dialysis Quality Initiative

From the Department of Intensive Care ${ }^{\mathrm{a}}$ and Cardiac Surgery, ${ }^{\mathrm{c}}$ Austin Health, Melbourne, Australia; the Department of Intensive Care and Nephrology, ${ }^{\mathrm{b}}$ Charité University Medicine, Berlin, Germany; and the Department of Intensive Care, ${ }^{\mathrm{d}}$ Ospedale Uboldo, Cernusco sul Naviglio, Italy.

Dr Haase holds a postdoctoral Feodor-Lynen Research Fellowship from the Alexander von Humboldt Foundation, Germany. This study was partly funded by a grant from the Australian and New Zealand College of Anaesthetists and by the Austin Hospital Anaesthesia and Intensive Care Trust Fund.

Received for publication March 24, 2009; revisions received May 28, 2009; accepted for publication July 1, 2009; available ahead of print Sept 7, 2009.

Address for reprints: Michael Haase, MD, Department of Intensive Care and Nephrology, Charité-University Medicine Berlin, Campus Virchow-Klinikum, Berlin, 13353, Germany (E-mail: michael.haase@charite.de).

$0022-5223 / \$ 36.00$

Copyright (C) 2009 by The American Association for Thoracic Surgery doi:10.1016/j.jtcvs.2009.07.007 group developed a consensus definition and classification of AKI: the RIFLE (R-renal risk, I-injury, F-failure, L-loss of kidney function, E-end-stage renal disease) classification system. ${ }^{2}$ This system defines and stages AKI based on creatinine value increase and decrease in glomerular filtration rate or urine output.

More recently, in an attempt to refine this approach, RIFLE was modified by the Acute Kidney Injury Network (AKIN) by including a shorter time frame within which AKI has to occur (48 hours), a milder serum creatinine value increase of greater than $0.3 \mathrm{mg} / \mathrm{dL}$ from baseline to peak value, ${ }^{1}$ and the staging of patients receiving renal replacement therapy as AKIN class $3 .^{3}$

The RIFLE classification has been investigated for its prognostic value for in-hospital mortality in more than 200,000 critically ill patients, ${ }^{4-7}$ patients undergoing cardiothoracic surgery, ${ }^{8,9}$ trauma patients, ${ }^{10}$ or hospitalized patients. ${ }^{11}$ The AKIN classification has been investigated in heterogeneous groups of critically ill patients ${ }^{4,5,12,13}$ but not in patients undergoing cardiac surgery. In most studies the RIFLE and AKIN classifications and their classes were found to be associated with progressively increasing mortality. ${ }^{4,7,11}$ To date, there is an intense debate over which definition and staging system should be used for AKI after cardiovascular surgery. 


\section{Abbreviations and Acronyms \\ AKI = acute kidney injury \\ AKIN $=$ Acute Kidney Injury Network \\ AUC-ROC $=$ area under the receiver operating characteristic curve \\ ICU = intensive care unit \\ RIFLE = R-renal risk, I-injury, F-failure, \\ L-loss of kidney function, \\ E-end-stage renal disease}

Neither classification, however, has been compared with the other regarding its ability to measure the incidence of AKI and predict patient outcomes after cardiac surgery. In this study we assessed and compared the RIFLE with the AKIN classifications with regard to the detection of AKI, their agreement according to grading of AKI across classes, and their prognostic value.

\section{MATERIALS AND METHODS Patient Population}

In a prospective cohort study from June 2007 to December 2007, we prospectively enrolled consecutive patients undergoing cardiac surgery with cardiopulmonary bypass at a tertiary hospital. Procedures included isolated coronary artery bypass grafting, isolated valve surgery, simultaneous coronary artery bypass grafting and valve surgery, and thoracic aortic surgery. We excluded patients with end-stage renal disease undergoing chronic hemodialysis, patients undergoing renal transplantation, patients enrolled in a conflicting research study, and patients younger than 18 years. This study adhered to the Declaration of Helsinki. The institutional ethics committee of the Austin Hospital granted permission to collect data for this study. Informed consent was obtained from each participant before enrollment.

\section{Patient Treatment}

Clinical practice was not changed or modified for study purposes. No special treatment in an attempt to prevent AKI was applied. Patients were intraoperatively hemodynamically monitored. Hemodynamic management targeted a mean arterial pressure of greater than $70 \mathrm{~mm} \mathrm{Hg}$, a cardiac index of greater than $2.5 \mathrm{~L} \cdot \min ^{-1} \cdot \mathrm{m}^{-2}$ as measured with use of a pulmonary artery catheter, and a central venous pressure of between 12 and $16 \mathrm{~cm}$ $\mathrm{H}_{2} \mathrm{O} .{ }^{14}$ Postoperatively in the intensive care unit (ICU), patients were maintained sedated, intubated, ventilated, and slowly rewarmed for at least the first 4 hours. Analgesia was achieved with acetaminophen and morphine or tramadol with avoidance of nonsteroidal anti-inflammatory drugs. In case of high thoracic drainage or bleeding complications, patients received tranexamic acid (Pfizer, Sydney, Australia), $1 \mathrm{~g}$ administered intravenously, preoperatively over 20 minutes and then $500 \mathrm{mg}$ dissolved in the pumpprime solution and $400 \mathrm{mg} / \mathrm{h}$ administered intravenously until arrival in the ICU. Urine output was maintained at 0.5 to $1 \mathrm{~mL} \cdot \mathrm{kg}^{-1} \cdot \mathrm{h}^{-1}$ by using fluids or furosemide, if necessary. Renal replacement therapy was initiated if the patient fulfilled at least 1 of the following clinical criteria: oliguria (urine output $<100 \mathrm{~mL}$ for $>6 \mathrm{hrs}$ ) that has been unresponsive to fluid resuscitation measures, hyperkalemia $\left(\left[\mathrm{K}^{+}\right]>6.5 \mathrm{mmol} / \mathrm{L}\right)$, severe acidemia $(\mathrm{pH}<7.2)$, or clinically significant organ edema (eg, lung) in the setting of renal failure.

\section{Data Collection}

We prospectively collected data on age, sex, height, weight, the presence or absence of arterial hypertension, diabetes mellitus (on medication), type of cardiac surgery, hemodynamic and fluid management, length of stay in the ICU and in the hospital, the need for renal replacement therapy, and in-hospital mortality.

Measurement of serum creatinine and urine output and estimation of glomerular filtration rate. Serum creatinine was measured preoperatively every 12 hours on the first postoperative day and daily thereafter by using the modified Jaffe method (Beckman Coulter Synchron LX System; Beckman Coulter, Inc, Brea, Calif) with an interassay and intra-assay coefficient of variation of less than $4 \% .{ }^{15}$ Urine output was documented hourly during ICU stay. Preoperative renal impairment was defined as an estimated glomerular filtration rate of less than 60 $\mathrm{mL} / \mathrm{min}$ per $1.73 \mathrm{~m}^{2}$ by using the Modification of Diet in Renal Disease Study formula re-expressed for use with the serum creatinine values standardized to isotope dilution mass spectroscopy. ${ }^{16}$

Classification of AKI. For both AKI staging systems, the criteria associated with the highest possible AKI class were used (Table 1). Patients without evidence of AKI were classified as RIFLE class 0 or AKIN class 0 .

For the RIFLE classification, as previously published by the Acute Dialysis Quality Initiative, ${ }^{2}$ we allocated to each patient the maximal RIFLE class according to postoperative changes in renal function by using creatinine value increase or decrease in estimated glomerular filtration rate ${ }^{8}$ within 7 days postoperatively or urine output reduction during ICU stay.

For the AKIN classification, as previously proposed by the $\mathrm{AKIN},{ }^{3}$ we allocated maximal AKIN class according to postoperative changes in renal function by using creatinine increase, need for renal replacement therapy, and urine output decrease within 48 hours postoperatively.

\section{Statistics}

The proportions of patients with AKI defined by the RIFLE (total, R, I, or F) or AKIN (total, 1, 2, or 3) classifications and other nominal data, such as the number of patients needing renal replacement therapy or who died in the hospital, were compared by using Fisher's exact test or the $\chi^{2}$ test as appropriate. The RIFLE and AKIN classifications and their components were assessed in relation to demographic data, distribution of comorbidities, type of cardiac surgery, hemodynamic and fluid management, length of stay in the ICU and the hospital, renal replacement therapy initiation, and in-hospital mortality. We further assessed the RIFLE and AKIN definitions and their single classes on their ability to predict in-hospital mortality by means of calculation of the area under the receiver operating characteristic curve (AUC-ROC). An AUC-ROC value of 0.90 to 1.0 indicated excellent, 0.80 to 0.89 indicated good, 0.70 to 0.79 indicated fair, 0.60 to 0.69 indicated poor, and 0.50 to 0.59 indicated no useful value. AUC-ROC values were compared according to the method of Hanley and McNeil. ${ }^{17}$ For comparison of the predictive value of the RIFLE classification with that of AKIN, we estimated that at an $\alpha$ value of .05, a sample size of 256 patients would be necessary to achieve an $80 \%$ power to detect a difference in AUC-ROC values of 0.1 performance units. Considering a loss to follow-up of $10 \%, 282$ patients were enrolled. We used SPSS Version 16.0 software (SPSS, Inc, Chicago, Ill) and MedCalc Version 9.3.9.0 software (MedCalc Software, Mariakerke, Belgium) for statistical analysis.

\section{RESULTS \\ Patient Characteristics}

We enrolled 282 patients. Preoperative patient characteristics, type of operation, and outcomes are presented in Table 2. With worsening RIFLE or AKIN stage, patients were significantly older, presented more frequently with comorbidities (eg, preoperative chronic kidney disease), more frequently underwent concomitant cardiac surgery, had increased lengths of stay in the ICU and hospital, and 
TABLE 1. Classification systems for acute kidney injury

\begin{tabular}{|c|c|c|c|c|c|}
\hline \multirow[b]{2}{*}{ Class } & \multicolumn{2}{|c|}{ RIFLE criteria* (within 7 d) } & \multirow[b]{2}{*}{ Stage } & \multicolumn{2}{|c|}{ AKIN criteria $\nmid$ (within $48 \mathrm{~h}$ ) } \\
\hline & GFR & Urine output & & Creatinine value & Urine output \\
\hline R-Risk & $\begin{array}{l}\text { Creatinine increase } \times 1.5 \text { or } \\
\text { GFR loss }>25 \%\end{array}$ & $<0.5 \mathrm{~mL} \cdot \mathrm{kg}^{-1} \cdot \mathrm{h}^{-1} \times>6 \mathrm{~h}$ & 1 & $\begin{array}{l}\text { Creatinine increase } \times 1.5 \text { or } \\
\text { creatinine increase } \\
>0.3 \mathrm{mg} / \mathrm{dL}\end{array}$ & $<0.5 \mathrm{~mL} \cdot \mathrm{kg}^{-1} \cdot \mathrm{h}^{-1} \times>6 \mathrm{~h}$ \\
\hline I-Injury & $\begin{array}{l}\text { Creatinine increase } \times 2 \text { or } \\
\text { GFR loss }>50 \%\end{array}$ & $<0.5 \mathrm{~mL} \cdot \mathrm{kg}^{-1} \cdot \mathrm{h}^{-1} \times>12 \mathrm{~h}$ & 2 & Creatinine increase $\times 2$ or & $<0.5 \mathrm{~mL} \cdot \mathrm{kg}^{-1} \cdot \mathrm{h}^{-1} \times>12 \mathrm{~h}$ \\
\hline F-Failure & $\begin{array}{l}\text { Creatinine increase } \times 3 \text { or } \\
\text { GFR loss }>75 \% \text { or } \\
\text { creatinine increase }>4 \\
\mathrm{mg} / \mathrm{dL} \text { (acute increase }>0.5 \\
\mathrm{mg} / \mathrm{dL} \text { ) }\end{array}$ & $\begin{array}{l}<0.3 \mathrm{~mL} \cdot \mathrm{kg}^{-1} \cdot \mathrm{h}^{-1} \times>24 \mathrm{~h} \\
\quad \text { or anuria }>12 \mathrm{~h}\end{array}$ & $3 \ddagger$ & $\begin{array}{l}\text { Creatinine increase } \times 3 \text { or } \\
\text { creatinine increase }>4 \\
\mathrm{mg} / \mathrm{dL} \text { (acute increase } \\
>0.5 \mathrm{mg} / \mathrm{dL} \text { ) }\end{array}$ & $\begin{array}{l}<0.3 \mathrm{~mL} \cdot \mathrm{kg}^{-1} \cdot \mathrm{h}^{-1} \times>24 \mathrm{~h} \\
\quad \text { or anuria }>12 \mathrm{~L}\end{array}$ \\
\hline L-Loss & $\begin{array}{l}\text { Persistent loss of kidney } \\
\text { function }>4 \mathrm{wk}\end{array}$ & & l & & \\
\hline $\begin{array}{l}\text { E-End-stage } \\
\text { renal disease }\end{array}$ & End-stage renal disease $>3$ mo & & / & & \\
\hline
\end{tabular}

increasingly needed postoperative renal replacement therapy (Table 2). During the first 24 hours postoperatively, the lowest mean arterial pressure and cardiac index also successively decreased with increasing kidney injury (Table 2).

The majority of patients had serum creatinine value increases of greater than $50 \%$ or greater than $0.3 \mathrm{mg} / \mathrm{dL}$ from baseline within the first 3 days postoperatively (Figure1). All patients with a serum creatinine value increase of greater than $50 \%$ had increments of greater than $0.3 \mathrm{mg} / \mathrm{dL}$.

\section{Detection of AKI According to Classification Systems: Totals and Agreement Across Classes}

A similar proportion of patients had AKI according to the RIFLE $(45.8 \%)$ or AKIK (44.7\%) classifications. Specifically, 85 (30.1\%) patients had RIFLE-R and $95(33.7 \%)$ patients had AKIN-1 $(P=0.366), 34(12.1 \%)$ patients had RIFLE-I and $19(6.7 \%)$ patients had AKIN-2 $(P=.022)$, and $10(3.5 \%)$ patients had RIFLE-F and $12(4.3 \%)$ patients had AKIN-3 $(P=.664)$ disease, respectively.

As seen in Table 3, there was relatively large overall agreement of the RIFLE and AKIN classifications. Both staged the same 146 patients as not having AKI, misclassifying less than $10 \%$ of patients. For example, only 9 $(5.8 \%)$ patients graded as having no renal impairment by using the AKIN classification were classified as having AKI by using the RIFLE classification, with nearly all of them belonging to class R. On the other hand, $6(4.0 \%)$ patients classified as normal by using the RIFLE classification were determined to have AKI by using the AKIN classification, with all of them in stage 1. This group consisted of patients showing a low preoperative serum creatinine value $(<0.7 \mathrm{mg} / \mathrm{dL})$ and reaching AKIN stage 1 because of a greater than $0.3 \mathrm{mg} / \mathrm{dL}$ serum creatinine value increase.
The largest disagreement $(13.7 \%)$ was found for grading patients as AKI stage 1 while being classified as RIFLE class $\mathrm{I}(\mathrm{n}=13$, Table 3$)$. Most of these patients had a greater than $50 \%$ increase in serum creatinine values (RIFLE) on postoperative days 3 to 7 .

\section{Prognostic Value}

With worsening RIFLE or AKIN stage, patients had increasing in-hospital mortality (Table 2). Only patients with AKI died during hospitalization.

In Table 4 we show the predictive value of the RIFLE and AKIN classifications for in-hospital mortality. The AUCROC value was similar for the totals of the classifications (0.91 vs $0.94, P=.6$ ). Worsening AKI class was associated with increased AUC-ROC values to predict mortality (Table 4).

Serum creatinine-based RIFLE or AKIN classes were the strongest predictors of in-hospital mortality (Table 4). The estimated glomerular filtration rate criteria added 13 patients to RIFLE class R, 4 patients to class I, and no patients to class F. Overall, the urine output criteria of the RIFLE or AKIN classification showed the lowest predictive value for in-hospital mortality (Table 4). However, if patients were classified as RIFLE-F or AKIN-3 for the urine output criteria compared with those with better diuresis, they had significantly longer lengths of stay in the ICU and the hospital and increased need for renal replacement therapy initiation and in-hospital mortality (Table 5).

Postoperative renal replacement therapy was initiated in 9 patients (Table 6). In most of them, the urine output criteria determined their maximal RIFLE class. In patients receiving renal replacement therapy, hospital survival was $44.4 \%$. Two patients required renal replacement therapy for more than 4 weeks (RIFLE-L), and 1 patient required renal replacement therapy for more than 3 months (RIFLE-E). 
TABLE 2. Perioperative characteristics

\begin{tabular}{|c|c|c|c|c|c|c|c|c|c|c|}
\hline & \multicolumn{5}{|c|}{ RIFLE } & \multicolumn{5}{|c|}{ AKIN } \\
\hline & $\begin{array}{c}0 \\
(\mathbf{n}=\mathbf{1 5 3})\end{array}$ & $\begin{array}{c}\mathbf{R} \\
(\mathbf{n}=\mathbf{8 5})\end{array}$ & $\begin{array}{c}\text { I } \\
(\mathbf{n}=\mathbf{3 4})\end{array}$ & $\begin{array}{c}\mathbf{F} \\
(\mathbf{n}=\mathbf{1 0})\end{array}$ & $\begin{array}{c}P \\
\text { value }\end{array}$ & $\begin{array}{c}0 \\
(n=156)\end{array}$ & $\begin{array}{c}1 \\
(n=95)\end{array}$ & $\begin{array}{c}2 \\
(n=19)\end{array}$ & $\begin{array}{c}3 \\
(n=12)\end{array}$ & $\begin{array}{c}P \\
\text { value } \\
\end{array}$ \\
\hline Age, y & $66.6 \pm 10.0$ & $69.5 \pm 9.4$ & $72.4 \pm 9.7$ & $77.6 \pm 5.3$ & $<.001$ & $66.4 \pm 10.5$ & $70.1 \pm 8.3$ & $72.2 \pm 9.8$ & $76.4 \pm 6.4$ & $<.001$ \\
\hline Female sex, no. & $51(33.3 \%)$ & $23(27.1 \%)$ & $10(29.4 \%)$ & $1(10.0 \%)$ & .383 & $54(34.6 \%)$ & $22(23.2 \%)$ & $7(36.8 \%)$ & $2(16.7 \%)$ & .154 \\
\hline $\begin{array}{l}\text { Preoperative kidney } \\
\text { disease, no. }\end{array}$ & $30(19.6 \%)$ & $22(25.9 \%)$ & $12(35.3 \%)$ & $6(60.0 \%)$ & .012 & $29(18.6 \%)$ & $26(27.4 \%)$ & $7(36.8 \%)$ & $7(58.3 \%)$ & .007 \\
\hline $\begin{array}{l}\text { Arterial } \\
\text { hypertension, no. }\end{array}$ & $128(83.7 \%)$ & $75(88.2 \%)$ & $32(94.1 \%)$ & $10(100 \%)$ & .203 & $130(83.3 \%)$ & $83(87.4 \%)$ & $19(100 \%)$ & $12(100 \%)$ & .116 \\
\hline $\begin{array}{l}\text { Diabetes mellitus, } \\
\text { no.* }\end{array}$ & $36(23.5 \%)$ & $23(27.1 \%)$ & $14(41.2 \%)$ & $3(16.7 \%)$ & .217 & $36(23.1 \%)$ & $28(29.5 \%)$ & $8(42.1 \%)$ & $4(33.3 \%)$ & .278 \\
\hline CABG surgery, no. & $64(41.8 \%)$ & $40(47.1 \%)$ & $14(41.2 \%)$ & $3(30.0 \%)$ & .707 & $65(41.7 \%)$ & $45(47.4 \%)$ & $7(36.8 \%)$ & $4(33.3 \%)$ & .668 \\
\hline $\begin{array}{l}\text { Valvular surgery, } \\
\text { no. }\end{array}$ & $69(45.1 \%)$ & $29(34.1 \%)$ & $9(26.5 \%)$ & $1(10.0 \%)$ & .029 & $65(41.7 \%)$ & $36(37.9 \%)$ & $5(26.3 \%)$ & $1(8.3 \%)$ & .086 \\
\hline $\begin{array}{l}\text { CABG and valve } \\
\text { surgery, no. }\end{array}$ & $8(5.2 \%)$ & $12(14.1 \%)$ & $8(23.5 \%)$ & $6(60.0 \%)$ & $<.001$ & $11(7.1 \%)$ & $11(11.6 \%)$ & $6(31.6 \%)$ & $6(50.0 \%)$ & $<.001$ \\
\hline $\begin{array}{c}\text { Thoracic aortic } \\
\text { surgery, no. }\end{array}$ & $13(8.5 \%)$ & $4(4.7 \%)$ & $4(11.8 \%)$ & $0(0.0 \%)$ & .408 & $15(9.6 \%)$ & $3(3.2 \%)$ & $1(5.3 \%)$ & $1(8.3 \%)$ & .271 \\
\hline $\begin{array}{l}\text { Mean arterial } \\
\text { pressure, } \\
\mathrm{mm} \mathrm{Hg} \dagger\end{array}$ & $65.2 \pm 9.6$ & $61.0 \pm 10.0$ & $61.8 \pm 8.9$ & $57.2 \pm 12.2$ & .001 & $64.8 \pm 9.7$ & $61.8 \pm 9.4$ & $63.7 \pm 6.7$ & $52.3 \pm 14.6$ & $<.001$ \\
\hline $\begin{array}{l}\text { Lowest cardiac } \\
\text { index, } \mathrm{L} \cdot \mathrm{min}^{-1} \text {. } \\
\mathrm{m}^{-2} \dagger\end{array}$ & $2.37 \pm 0.43$ & $2.19 \pm 0.39$ & $2.13 \pm 0.47$ & $2.29 \pm 0.51$ & .004 & $2.35 \pm 0.41$ & $2.19 \pm 0.41$ & $2.17 \pm 0.37$ & $2.16 \pm 0.57$ & .011 \\
\hline $\begin{array}{l}\text { Infusion } \\
\quad \text { volume, } \mathrm{mL} \dagger\end{array}$ & $5430 \pm 1400$ & $5760 \pm 1500$ & $5440 \pm 1760$ & $6840 \pm 1500$ & .017 & $5510 \pm 1430$ & $5560 \pm 1450$ & $5300 \pm 1660$ & $7300 \pm 1760$ & .001 \\
\hline Furosemide, $\mathrm{mg} \dagger$ & $15(0-30)$ & $25(10-50)$ & $49(10-100)$ & $115(24-237)$ & $<.001$ & $15(0-30)$ & $30(10-60)$ & $40(10-70)$ & $112(93-218)$ & $<.001$ \\
\hline $\begin{array}{l}\text { Length of stay } \\
\text { in the intensive } \\
\text { care unit, } \mathrm{h}\end{array}$ & $43(22-48)$ & $46(29-71)$ & $71(50-111)$ & $261(112-429)$ & $<.001$ & $43(22-48)$ & $47(36-72)$ & $69(50-88)$ & $348(120-431)$ & $<.001$ \\
\hline $\begin{array}{l}\text { Length of stay in } \\
\text { hospital, d }\end{array}$ & $7(7-9)$ & $8(7-11)$ & $9(7-13)$ & $25(13-35)$ & $<.001$ & $7(7-9)$ & $8(7-11)$ & $9(8-13)$ & $22(12-40)$ & $<.001$ \\
\hline $\begin{array}{l}\text { Need for renal } \\
\text { replacement } \\
\text { therapy, } \\
\text { no. }(\%)\end{array}$ & $0(0.0)$ & $1(1.2)$ & $2(5.9)$ & $6(60.0)$ & $<.001$ & $0(0.0)$ & $0(0.0)$ & $0(0.0)$ & $9(75.0)$ & $<.001 \ddagger$ \\
\hline $\begin{array}{l}\text { Died during } \\
\text { hospital stay, } \\
\text { no. }(\%)\end{array}$ & $0(0.0)$ & $1(1.2)$ & $3(8.8)$ & $2(20.0)$ & $<.001$ & $0(0.0)$ & $1(1.1)$ & $0(0.0)$ & $5(41.7)$ & $<.001$ \\
\hline
\end{tabular}

Linear values denote means \pm standard deviations. RIFLE, R-renal risk, I-injury, F-failure, L-loss of kidney function, E-end-stage renal disease; AKIN, Acute Kidney Injury Network; $C A B G$, coronary artery bypass grafting. *Diabetes mellitus includes patients receiving oral antidiabetics or insulin. $\nmid$ Zero to 24 hours postoperatively includes pump-

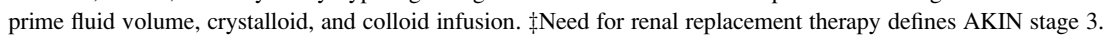

\section{DISCUSSION}

We conducted a prospective study to compare and clarify the diagnostic and prognostic value of the RIFLE and AKIN classifications for AKI after cardiac surgery. Only patients with AKI as defined by these classifications needed renal replacement therapy or died during hospitalization. Despite significantly fewer patients having AKIN stage 2 disease compared with RIFLE-I disease, we found a similar overall proportion of patients with AKI and a similar prognostic value for inhospital mortality. In this regard the AKI definitions assessed in this study were essentially of similar diagnostic and prognostic value. There was large agreement between classifications according to patients graded as not having AKI; however, there was some disagreement across classes for AKI severity.

The value of the RIFLE or AKIN classification for patient risk stratification has been investigated in mostly septic patients. ${ }^{4-6,12,18}$ Of those, some reported on either the RIFLE ${ }^{19}$ or the AKIN classification, whereas others compared them and found both to be of similar value and sensitivity. ${ }^{4,5}$ In 2 studies the RIFLE classification was investigated in patients undergoing cardiac surgery ${ }^{8,19}$ and was found to be an independent predictor for 90-day mortality. ${ }^{8}$

Most of these previous studies used the creatinine criteria $^{9,11,19}$ and some used the urine output criteria ${ }^{4,5,8}$ for 


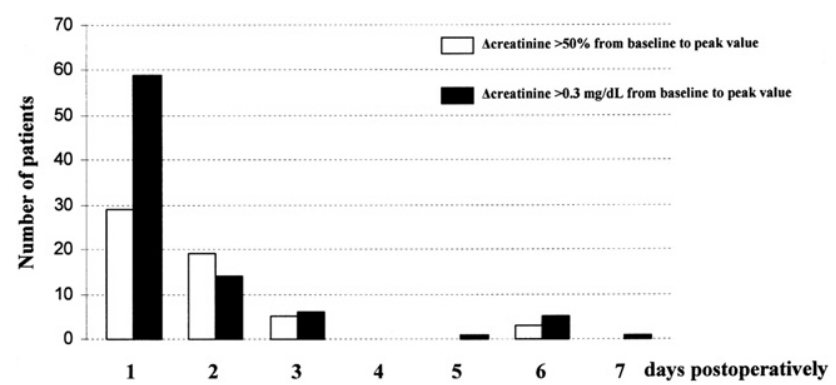

FIGURE 1. Timing of increase in serum creatinine value within 7 days postoperatively.

allocation of patients to RIFLE classes. In studies in which data on urine output were available, it was mostly for 24hour intervals only, ${ }^{4}$ making correct staging impossible. None of the previous publications assessed and compared full definitions in patients undergoing cardiac surgery, a major cause of AKI. ${ }^{20}$ All studies in thoracic surgery on the RIFLE classification have included acute aortic dissection as a subgroup and thus have been unable to escape the confounding effects of the mixed aortic arch cohort. ${ }^{21}$

Because of the recent proposal for a second AKI classification by the AKIN and no direct comparison using the full definition of these classifications in adult patients undergoing cardiac surgery, specifically in patients undergoing cardiac surgery there is continuing uncertainty about the relative merits of each classification system. We now provide such data.

As with several studies before, ${ }^{7,8,11}$ we found a strong predictive value of the degree of AKI defined by the RIFLE classification for in-hospital mortality. Consistent with findings from a large study using fragments of the RIFLE and AKIN classifications, ${ }^{4}$ there was no additional diagnostic value, prognostic value, or both of the AKIN definition over the RIFLE system.
TABLE 3. Agreement of AKIN with RIFLE classifications according to identification of AKI across classes

\begin{tabular}{llrrccr}
\hline & & \multicolumn{5}{c}{ RIFLE } \\
\cline { 3 - 7 } & & No AKI & Risk & Injury & Failure & Total \\
\hline AKIN & No AKI & 146 & 8 & 0 & 1 & 155 \\
& Stage 1 & 6 & 76 & 13 & 0 & 95 \\
& Stage 2 & 0 & 0 & 19 & 0 & 19 \\
& Stage 3 & 0 & 1 & 2 & 9 & 12 \\
& Total & 152 & 85 & 34 & 10 & 282 \\
\hline
\end{tabular}

$A K I N$, Acute Kidney Injury Network; RIFLE, R-renal risk, I-injury, F-failure, L-loss of kidney function, E-end-stage renal disease; $A K I$, acute kidney injury.

However, direct comparison of the 3 AKI classification systems revealed flaws on either side. Despite sufficient overall agreement between classifications regarding the staging of patients who did not have AKI, there was variation between classifications in the allocation for patients to a given stage of AKI. For example, 13 patients classified as AKIN stage 1 were classified as RIFLE class I because their serum creatinine values increased progressively after 48 hours postoperatively. Also, 2 patients classified as RIFLE class I were staged as AKIN class 3 because renal replacement therapy was initiated. Therefore the agreement between classifications across classes appears to be limited and inherent to the different definition (magnitude and timing) of the creatinine-related criteria and the different staging triggered by use of renal replacement therapy. Compared with the AKIN definition, in which the peak serum creatinine value can only be assessed as a measure of injury during the first 48 hours after cardiac surgery, the RIFLE criteria are not dependent on such a rapid change. This might be of importance in patients who experience their peak serum creatinine value from day 3 onward because their maximum level of AKI will be missed by using the

TABLE 4. Association of RIFLE or AKIN classifications with mortality

\begin{tabular}{|c|c|c|c|c|c|c|c|c|}
\hline & RIFLE & $\mathbf{R}^{*}$ & $\mathbf{I}^{*}$ & $\mathbf{F}^{*}$ & AKIN & $\mathbf{1}^{*}$ & $2 *$ & 3* \\
\hline & \multicolumn{4}{|c|}{ RIFLE classes (total) } & \multicolumn{4}{|c|}{ AKIN stages (total) } \\
\hline $\begin{array}{l}\text { AUC-ROC } \\
\quad(95 \% \mathrm{CI})\end{array}$ & $\begin{array}{c}0.91 \\
(0.82-0.99)\end{array}$ & $\begin{array}{c}0.82 \\
(0.62-0.99)\end{array}$ & $\begin{array}{c}0.91 \\
(0.84-0.98)\end{array}$ & $\begin{array}{c}0.97 \\
(0.88-0.99)\end{array}$ & $\begin{array}{c}0.94 \\
(0.81-0.97)\end{array}$ & $\begin{array}{c}0.81 \\
(0.59-0.99)\end{array}$ & $-\dagger$ & $\begin{array}{c}0.98 \\
(0.89-1.00)\end{array}$ \\
\hline \multirow[t]{2}{*}{$P$ value } & .001 & .266 & .016 & .022 & $<.001$ & .283 & & $<.001$ \\
\hline & \multicolumn{4}{|c|}{ RIFLE classes (creatinine value increase) } & \multicolumn{4}{|c|}{ AKIN stages (creatinine value increase) } \\
\hline $\begin{array}{l}\text { AUC-ROC } \\
\quad(95 \% \text { CI }) \\
P \text { value }\end{array}$ & $\begin{array}{c}0.93 \\
(0.88-0.97) \\
<.001\end{array}$ & $\begin{array}{c}0.95 \\
(0.89-0.99) \\
.030\end{array}$ & $\begin{array}{c}0.97 \\
(0.91-0.99) \\
.001\end{array}$ & $-\ddagger$ & $\begin{array}{c}0.88 \\
(0.81-0.95) \\
.001\end{array}$ & $\begin{array}{c}0.88 \\
(0.81-0.96) \\
.008\end{array}$ & $\begin{array}{c}0.98 \\
(0.91-0.99) \\
.021\end{array}$ & $-\ddagger$ \\
\hline$P$ value & \multicolumn{4}{|c|}{ RIFLE classes (urine output) } & \multicolumn{4}{|c|}{ AKIN stages (urine output) } \\
\hline $\begin{array}{l}\text { AUC-ROC } \\
\quad(95 \% \mathrm{CI})\end{array}$ & $\begin{array}{c}0.76 \\
(0.51-0.99)\end{array}$ & $\begin{array}{c}0.56 \\
(0.21-0.90)\end{array}$ & $\begin{array}{c}0.64 \\
(0.27-0.97)\end{array}$ & $\begin{array}{c}0.70 \\
(0.40-0.99)\end{array}$ & $\begin{array}{c}0.76 \\
(0.51-0.99)\end{array}$ & $\begin{array}{c}0.56 \\
(0.21-0.90)\end{array}$ & $\begin{array}{c}0.64 \\
(0.27-0.97)\end{array}$ & $\begin{array}{c}0.70 \\
(0.40-0.99)\end{array}$ \\
\hline$P$ value & .030 & .734 & .395 & .136 & .030 & .734 & .395 & .136 \\
\hline
\end{tabular}


TABLE 5. Comparison of patients' outcomes according to the urine output criteria of the RIFLE versus AKIN classifications

\begin{tabular}{|c|c|c|c|}
\hline RIFLE class/AKIN class & $\begin{array}{c}, \mathbf{F}^{\prime} / 3 \\
(\mathbf{n}=\mathbf{5})\end{array}$ & $\begin{array}{c}\mathbf{0} / \mathbf{0},, \mathbf{R}^{\prime} / \mathbf{1},, \mathbf{I}^{\prime} / \mathbf{2} \\
(\mathbf{n}=\mathbf{2 7 7})\end{array}$ & $P$ value \\
\hline $\begin{array}{l}\text { Length of stay in intensive } \\
\text { care unit, } h\end{array}$ & $266.6 \pm 162.1$ & $64.9 \pm 88.2$ & .001 \\
\hline Length of stay in hospital, $d$ & $20.4 \pm 13.1$ & $9.7 \pm 7.3$ & .001 \\
\hline $\begin{array}{l}\text { Need for renal replacement } \\
\text { therapy, no. }\end{array}$ & $5(100 \%)$ & $4(1.4 \%)$ & $<.001$ \\
\hline Died during hospital stay, no. & $2(40.0 \%)$ & $4(1.4 \%)$ & .004 \\
\hline
\end{tabular}

The urine output criteria of both classifications apply the same cutoff values in urine output to allocate a patient to an acute kidney injury category. RIFLE, R-renal risk, I-injury, F-failure, L-loss of kidney function, E-end-stage renal disease; $A K I N$, Acute Kidney Injury Network; $A U C-R O C$, area under the receiver operating characteristic curve.; AKIN, Acute Kidney Injury Network.

AKIN criteria but detected by using the RIFLE criteria, an effect that might have contributed to the largest disagreement observed when comparing the RIFLE and AKIN classifications. The RIFLE criteria L and E allow long-term follow-up of kidney function after cardiac surgery. On the other hand, one might argue that the AKIN classification, by using an early greater than $0.3 \mathrm{mg} / \mathrm{dL}$ creatinine value increase, identifies more patients already during the first 48 hours postoperatively compared with the RIFLE classification during the same period.

The serum creatinine-based criteria had great discriminatory ability for in-hospital mortality. Similarly to Kuitunen and associates, ${ }^{8}$ despite its known limitations during acute changes in renal function, we found the estimated glomerular filtration rate criteria of importance for the RIFLE classification. In addition, several patients with RIFLE-F disease and associated worse clinical outcomes were identified by using the urine output criteria but not by using creatinine-based criteria, further supporting the logic of the original classification.
The incidence of AKI as defined by the RIFLE classification in this study was higher compared with that seen in a recent study of a similar cohort $(19.3 \%)^{8}$ but lower than that found in a large cohort of patients undergoing aortic arch surgery $(48 \%) .{ }^{9}$ The prognostic value of the RIFLE creatinine criteria in our study was similar to that of a previous study (AUC-ROC value $>0.85$ for mortality) ${ }^{8}$ but higher than that found on admission in critically ill patients (AUC-ROC value for mortality approximately 0.66 ).$^{10} \mathrm{In}$ critically ill patients, the timing of renal injury is unknown, and complete data collection is virtually impossible. This might provide a potential explanation for the lower discriminatory ability of an AKI classification system in this setting.

Several strengths and limitations apply to our study. We prospectively investigated a very recent cohort of patients. The prospective nature of this study ensured the completeness of data acquisition, including baseline serum creatinine concentrations and hourly collection of urine output volume. Thus this is the first study providing such detailed data and a direct comparison of the prognostic value for the RIFLE classification with the AKIN classification applied in patients undergoing cardiac surgery.

The population investigated was relatively homogeneous (cardiac surgery). Cardiopulmonary bypass surgery is among the 3 major causes for AKI. The sample size was relatively small, and the in-hospital mortality was low. Nonetheless, the study was powered to detect a clinically meaningful difference in prognostic utility. The study design does not allow the exploration of potential causes of postoperative AKI, such as intraoperative hemodynamic and fluid management.

The interpretation and comparability of future study results according to AKI severity with different AKI classifications might be hampered. This might constitute an important impediment to successful research on the improvement of outcomes

TABLE 6. Outcome of patients on postoperative renal replacement therapy for CSA-AKI

\begin{tabular}{|c|c|c|c|c|c|c|c|c|}
\hline $\begin{array}{c}\text { Patient } \\
\text { no. }\end{array}$ & Reason for RRT & Maximum RIFLE & Maximum AKIN & $\begin{array}{c}\text { Dose of } \\
\text { furosemide } \\
(0-48 \mathrm{~h}), \mathrm{mg}\end{array}$ & Ventilation, $\mathbf{h}$ & ICU, h & Hospital, d & $\begin{array}{c}\text { Survived } \\
\text { hospital } \\
\text { stay }\end{array}$ \\
\hline 1 & $\begin{array}{l}\text { Hyperkalemia, lactic } \\
\text { acidosis }\end{array}$ & crea-R, eGFR-I, UO-0 & crea-1, UO-0, RRT-3 & 125 & 70 & 113 & 5 & No \\
\hline 2 & Oliguria, fluid overload & crea-I, eGFR-I, UO-I & crea-1, UO-2, RRT-3 & 300 & 374 & 390 & 16 & No \\
\hline 3 & $\begin{array}{l}\text { Hyperkalemia, lactic } \\
\text { acidosis }\end{array}$ & crea-R, eGFR-R, UO-0 & crea-1, UO-0, RRT-3 & 210 & 970 & 1032 & 43 & No \\
\hline 4 & Oliguria, fluid overload & crea-R, eGFR-R, UO-F & crea-1, UO-3, RRT-3 & 560 & 46 & 185 & 26 & Yes \\
\hline 5 & Oliguria, fluid overload & crea-I, eGFR-I, UO-F & crea-2, UO-3, RRT-3 & 855 & 240 & 428 & 30 & Yes \\
\hline 6 & $\begin{array}{l}\text { Oligoanuria, fluid } \\
\text { overload }\end{array}$ & crea-I, eGFR-I, UO-F & crea-2, UO-3, RRT-3 & 200 & 15 & 24 & 1 & No \\
\hline 7 & Anuria, fluid overload & crea-0, eGFR-0, UO-F & crea-0, UO-3, RRT-3 & 20 & 95 & 360 & 32 & Yes \\
\hline 8 & Hyperkalemia, uremia & crea-F, eGFR-I, UO-R & crea-3, UO-1, RRT-3 & 1100 & 350 & 450 & 90 & Yes \\
\hline 9 & $\begin{array}{l}\text { Oligoanuria, fluid } \\
\text { overload }\end{array}$ & crea-I, eGFR-I, UO-F & crea-2, UO-3, RRT-3 & 300 & 306 & 336 & 13 & No \\
\hline
\end{tabular}

CSA-AKI, Cardiac surgery-associated acute kidney injury; RIFLE, R-renal risk, I-injury, F-failure, L-loss of kidney function, E-end-stage renal disease; AKIN, Acute Kidney Injury Network; $A U C-R O C$, area under the receiver operating characteristic curve.; $R R T$, renal replacement therapy; $A K I N$, Acute Kidney Injury Network; $I C U$, intensive care unit; crea, creatinine; $e G F R$, estimated glomerular filtration rate; $U O$, urine output. 
in patients with AKI. Finally, the causality of intraoperative and postoperative hemodynamic and fluid management on the development of AKI deserves further investigation.

In conclusion, this study supports the view that the recently proposed definition and classification systems for AKI are similarly useful in diagnosis and accurate in prognosis. It also implies that changes made to the original RIFLE definition and classifications do not carry substantial additional diagnostic or prognostic value in cardiac surgery patients. In the interest of meaningful comparison of study findings and of progress in AKI research, it appears to be advisable that only 1 AKI classification system should be referenced.

\section{References}

1. Chertow GM, Burdick E, Honour M, Bonventre JV, Bates DW. Acute kidney injury, mortality, length of stay, and costs in hospitalized patients. J Am Soc Nephrol. 2005; 16:3365-70.

2. Bellomo R, Ronco C, Kellum JA, Mehta RL, Palevsky P. Acute Dialysis Quality Initiative workgroup. Acute renal failure-definition, outcome measures, animal models, fluid therapy and information technology needs: the Second International Consensus Conference of the Acute Dialysis Quality Initiative (ADQI) Group. Crit Care. 2004;8:R204-12.

3. Mehta RL, Kellum JA, Shah SV, Molitoris BA, Ronco C, Warnock DG, et al. Acute Kidney Injury Network: report of an initiative to improve outcomes in acute kidney injury. Crit Care. 2007;11:R31.

4. Bagshaw SM, George C, Bellomo R. ANZICS Database Management Committee. A comparison of the RIFLE and AKIN criteria for acute kidney injury in critically ill patients. Nephrol Dial Transplant. 2008;23:1569-74.

5. Lopes JA, Fernandes P, Jorge S, Gonçalves S, Alvarez A, Costa e Silva Z, et al. Acute kidney injury in intensive care unit patients: a comparison between the RIFLE and the Acute Kidney Injury Network classifications. Crit Care. 2008; 12:R110.

6. Ostermann M, Chang R. Acute kidney injury in the intensive care unit according to RIFLE. Crit Care Med. 2007;35:1837-43.

7. Hoste EA, Clermont G, Kersten A, Venkataraman R, Angus DC, De Bacquer D, et al. RIFLE criteria for acute kidney injury are associated with hospital mortality in critically ill patients: a cohort analysis. Crit Care. 2006;10:R73.
8. Kuitunen A, Vento A, Suojaranta-Ylinen R, Pettilä V. Acute renal failure after cardiac surgery: evaluation of the RIFLE classification. Ann Thorac Surg. 2006;81:542-6.

9. Arnaoutakis GJ, Bihorac A, Martin TD, Hess PJ Jr, Klodell CT, Ejaz AA, et al. RIFLE criteria for acute kidney injury in aortic arch surgery. J Thorac Cardiovasc Surg. 2007;134:1554-61.

10. Bagshaw SM, George C, Gibney RT, Bellomo R. A multi-center evaluation of early acute kidney injury in critically ill trauma patients. Ren Fail. 2008;30:581-9.

11. Uchino S, Bellomo R, Goldsmith D, Bates S, Ronco C. An assessment of the RIFLE criteria for acute renal failure in hospitalized patients. Crit Care Med. 2006; 34:1913-7.

12. Ostermann M, Chang R. The Riyadh ICU Program Users Group. Correlation between the AKI classification and outcome. Crit Care. 2008;12:R144.

13. Barrantes F, Tian J, Vazquez R, Amateng-Adjepong Y, Manthous CA. Acute kidney injury criteria predict outcomes of critically ill patients. Crit Care Med. 2008; 36:1397-403.

14. Haase M, Haase-Fielitz A, Bagshaw SM, Reade MC, Morgera S, Seevenayagam S, et al. Phase II, randomized, controlled trial of high-dose N-acetylcysteine in high-risk cardiac surgery patients. Crit Care Med. 2007;35: 1324-31.

15. Haase M, Haase-Fielitz A, Ratnaike S, Reade MC, Bagshaw SM, Morgera S, et al. $\mathrm{N}$-Acetylcysteine does not artifactually lower plasma creatinine concentration. Nephrol Dial Transplant. 2008;23:1581-7.

16. Levey AS, Coresh J, Greene T, Marsh J, Stevens LA, Kusek JW, et al. Expressing the modification of diet in renal disease study equation for estimating glomerular filtration rate with standardized serum creatinine values. Clin Chem. 2007;53: 766-72.

17. Hanley JA, McNeil BJ. A method of comparing the areas under receiver operating characteristic curves derived from the same cases. Radiology. 1983;148:839-43.

18. Bagshaw SM, George C, Bellomo R. ANZICS Database Management Committee. Early acute kidney injury and sepsis: a multicentre evaluation. Crit Care. 2008;12:R47.

19. Lassnigg A, Schmidlin D, Mouhieddine M, Bachmann LM, Druml W, Bauer P, et al. Minimal changes of serum creatinine predict prognosis in patients after cardiothoracic surgery: a prospective cohort study. J Am Soc Nephrol. 2004;15: $1597-605$.

20. Uchino S, Kellum JA, Bellomo R, Doig GS, Morimatsu H, Morgera S, et al. Beginning and Ending Supportive Therapy for the Kidney (BEST Kidney) Investigators. Acute renal failure in critically ill patients: a multinational, multicenter study. JAMA. 2005;294:813-8.

21. Augoustides JGT. RIFLE criteria in aortic arch surgery: the further role of surgical subgroup. J Thorac Cardiovasc Surg. 2008;136:233. 